\title{
DETERMINAÇÃO DOS IMPACTOS AMBIENTAIS NA CONSTRUÇÃO DE UM SISTEMA HOTELEIRO NAS FALÉSIAS EM TIBAU DO SUL - RN
}

\author{
SCUDELARI, A.C \& FREIRE, L.C.S. \\ UFRN - Universidade Federal do Rio Grande do Norte
}

\begin{abstract}
Scudelari, A.C \& Freire, L.C.S. 2005. Determination the environmental impacts generated by the construction of a hotel system in the cliffs of Tbau do Sul - RN. Braz. J. Aquat. Sci. Technol. 9(1):39-43. ISSN 1808-7035. The implantation of tourist equipments in the borders of cliffs, fragile areas under the environmental point of view, it is constituted in an of the main causes of the use pressure and occupation of the soil of the coastal area. The need to control the population growth disordered in the municipal district of Tibau do Sul - RN, as well as in the whole coastal area of $\mathrm{RN}$, it has been promoting discussions in what refers to the implementation of a politics efficient and rational, because such environmental growth occurs of the tourist potential fort and of the implantation of activities human without any concern with the sustainability of the area. The objective of this work is, therefore to determine the environmental impacts generated by the construction of a hotel system in the cliffs of Tibau do Sul - RN. The district of Tibau do Sul, study area, is approximately located the $87 \mathrm{~km}$ to the south of the city of Natal, capital of the State of Rio Grande do Norte. The population concentrates mainly at coastal towns installed in the district of Tibau do Sul and Pipa and among the developed economical activities they are the fishing, the livestock and the tourism. The main ones negative impacts say respect a installation of erosive processes in the area and pollution of the water of the underground sheet and of the sea. The main positive impacts concern the socioeconomic development of the area. As reliever measures are suitable works of sanitation, territorial ordination and actions of control of the erosive processes.
\end{abstract}

Keywords: Emviromental impacts, Tibau do Sul, RN.

\section{INTRODUÇÃO}

O desenvolvimento do estado do Rio Grande do Norte se deu, nos últimos anos de forma vertiginosa em todas as áreas e atividades, destacando-se dentre elas o comércio, o turismo, a carcinicultura e tantos outros componentes que influenciam no crescimento do estado. O turismo na região desenvolveu-se de forma rápida e desordenada sendo, portanto, o grande responsável por alterações que promovem o surgimento de impactos ambientais, advindos da utilização de áreas frágeis, sem respeitar limitações impostas pelas autoridades. Por se tratar de uma APA - Área de Proteção Ambiental, sua utilização no que compete à implantação de empreendimentos turísticos deve ser precedida de um EIA - Estudo de Impacto Ambiental de forma a subsidiar a preservação ambiental da região e obter parâmetros técnicos que viabilizem a construção de equipamentos turísticos no ecossistema das falésias no município de Tibau do Sul. O número de empreendimentos turísticos instalados no estado duplicou nos últimos anos, tendo o litoral sul do estado, mais especificamente à região de Tibau do Sul, um aumento considerável na implantação de complexos hoteleiros. A região de Tibau do Sul, objeto de estudo deste trabalho, se configura em ambiente bastante frágil no que concerne à ocorrência de processos erosivos costeiros que culminam no recuo da linha de costa e na sus- ceptibilidade de riscos de colapsos devido à instalação de empreendimentos turísticos nas bordas das falésias.

\section{Área de estudo}

O município de Tibau do Sul está localizado a aproximadamente $87 \mathrm{~km}$ ao Sul da cidade de Natal, capital do Rio Grande do Norte. Sua população de 7750 habitantes (IDEMA,1999) está localizada principalmente nas vilas litorâneas de Tibau do Sul e Pipa, conforme mostrado na figura 1. Limita-se fisicamente ao Leste com o Oceano Atlântico; ao Sul com o canal do Rio Catú, que desemboca na região de Sibaúma; ao Oeste por uma linha que liga a região de Barraca, na bifurcação do Rio Catú até o limite ocidental da Laguna de Guaraíras; ao Norte pela margem sul da Laguna de Guaraíras.

Em termos econômicos, as principais atividades são a pesca, a pecuária e a crescente indústria do turismo, concentrada na zona costeira. A zona costeira do município de Tibau do Sul é caracterizada pela presença de falésias, dunas, praias arenosas e arenitos de praia na forma de cordões lineares (recifes). A beleza da região associada à pressão de uso e ocupação do solo tem acarretado um incremento na indústria do turismo, possibilitando uma aceleração desordenada na implantação de equipamentos turísticos ao longo da zona costeira, principalmente nas bordas das 


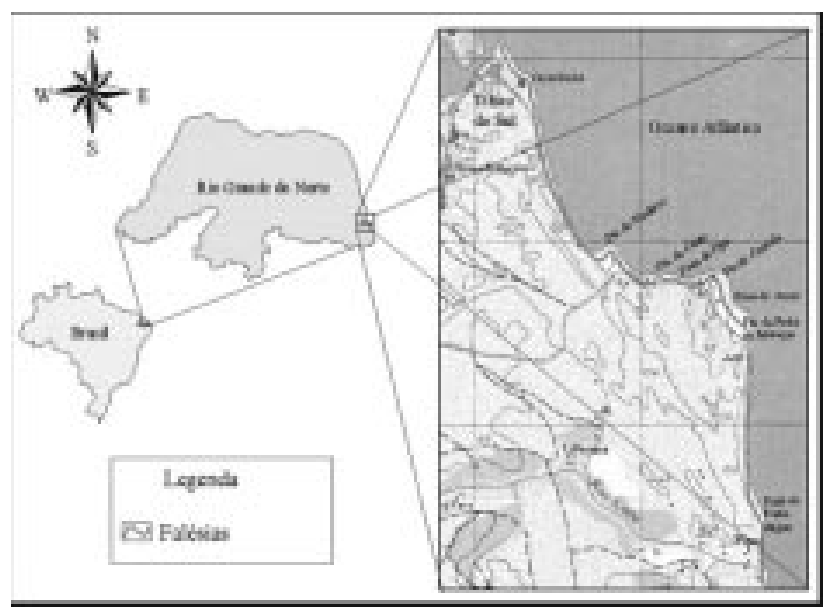

Figura 1 - Localização da área.

falésias e zona de praia. Verifica-se nesta região, como em toda a zona costeira, uma tendência natural de avanço da linha de costa em direção ao continente. A zona costeira se configura em uma das zonas mais dinâmicas do planeta e, sua forma e posição são sensíveis a uma série de fatores que vão desde as variações no nível do mar às precipitações pluviométricas. É nesta zona bastante frágil do ponto de vista ambiental, que surgem as intervenções antrópicas, principais causadoras de impactos ambientais no ecossistema em questão.

A fixação de empreendimentos nas bordas de falésias altera a topografia da região, o desmatamento acelera o processo de erosão pluvial, e interfere na trajetória do recuo natural da linha de costa. Desta forma, verifica-se um aumento no risco de destruição de tais empreendimentos devido ao processo de recuo. Os principais impactos negativos dizem respeito à instalação de processos erosivos na área e poluição da água do lençol subterrâneo e do mar. Os principais impactos positivos dizem respeito ao desenvolvimento socioeconômico da região. Como medidas mitigadoras são propostas obras de saneamento, ordenação territorial e ações de controle dos processos erosivos. Neste trabalho, trata-se de uma análise integrada dos aspectos físicos, bióticos e antrópicos, definindo assim as conseqüências geradas ou potencializadas com a instalação do complexo hoteleiro na região.

\section{MATERIAL E MÉTODOS}

A determinação dos impactos ambientais advindos da construção de um sistema hoteleiro nas falésias em Tibau do Sul partiu da caracterização da geomorfologia, geologia, recursos hídricos, vegetação, fauna e uso e ocupação do solo, além da definição da bacia de drenagem pluvial. Identificaram-se também aspectos sócio-econômicos locais e apontaram-se as repercussões ambientais e medidas mitigadoras dos impactos adversos do empreendimento, viabilizando a adequação o mesmo ao ecossistema, garantindo a sustentabilidade da área ao projeto proposto.

\section{DIAGNÓSTICO AMBIENTAL DA ÁREA}

\section{Meio Físico}

O meio físico corresponde ao solo, a topografia, a geologia, o clima e os recursos hídricos e, quaisquer alterações nesses fatores acarretam conseqüências positivas ou adversas. Aárea de estudo apresenta clima tropical sub-úmido (IDEMA, 1999). O clima aparece como responsável por modificações superficiais verificadas no tempo e no espaço. Tais modificações garantem a manutenção do equilíbrio dinâmico entre o relevo e os processos externos que sobre ele atuam. Os ventos, as chuvas e a temperatura interferem diretamente sobre o comportamento da cobertura vegetal, no que diz respeito ao seu poder de minimizar o desencadeamento de processos erosivos. A temperatura média anual de Tibau do Sul é de $25,6^{\circ} \mathrm{C}$, a precipitação pluviométrica média anual é de $1400 \mathrm{~mm}$, a estação chuvosa estende-se de janeiro a agosto e a umidade relativa do ar é de $74 \%$. (IDEMA, 1999). Os ventos são provenientes do quadrante SE e apresentam velocidades entre 3.8 e $5.4 \mathrm{~m} / \mathrm{s}$ (ventos mais fortes). As formas dunares presentes na região atestam tal comportamento dos ventos. No que compete à geologia, o município se insere na área de abrangência do Grupo Barreiras. As rochas são recobertas localmente por coberturas arenosas, que culminam na formação de solos permeáveis e lixiviados. As dunas são compostas por areias inconsolidadas e bem selecionadas de origem marinha trazidas pelos ventos, que podem ser fixadas por vegetação (dunas fixas) ou não (dunas móveis). Aárea de influência direta do empreendimento corresponde ao Tabuleiro Costeiro, onde ocorre relevo plano e suavemente ondulado. Este representa uma antiga posição da linha de costa que, tendo recuado ao longo do tempo, deixou como testemunho de sua ação erosiva as escarpas entalhadas da Formação Barreiras (falésias mortas). Ver fotos 1, 2 e 3.

Entre os principais riachos da região, estão o Olhos d'água e o Galhardo. A Lagoa de Guaraíras destaca-se como a principal lagoa, enquanto o Rio Catú e Piau aos rios principais. Em relação às Bacias Hidrográficas, $80 \%$ do município de Tibau do Sul encontra-se inserido na bacia do Rio Catú, $15 \%$ na bacia do Rio Jacu e 5\% na bacia do Rio Curimataú. A área do empreendimento se enquadra em uma bacia de drenagem aberta, onde se verifica escoamento superficial 


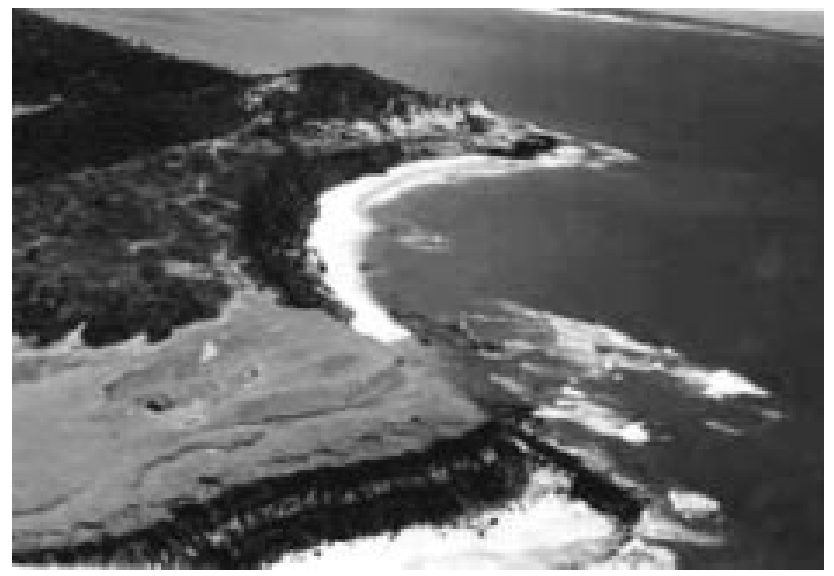

Foto 1 - Vista aérea do Chapadão.

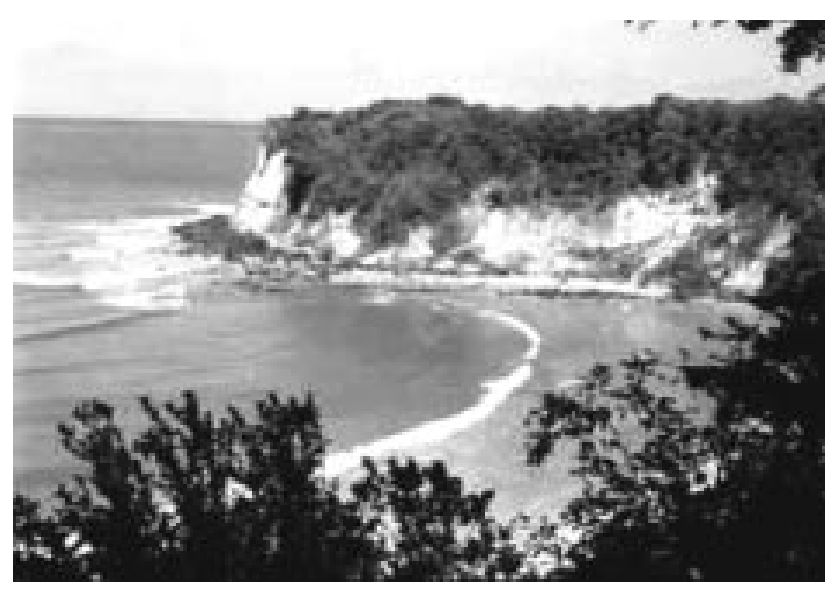

Foto 3 - Vista das falésias de Tibau do Sul.

das águas pluviais nas falésias. Tal fator potencializa os processos erosivos instalados na região se ações de caráter mitigador não forem tomadas com vistas a proteger e/ou preservar as falésias da região.

\section{Meio Biológico}

Dentre as coberturas vegetais presentes na região estão a Mata Atlântica, os manguezais e o tabuleiro litorâneo. A importância da Mata Atlântica para a região está no fato da mesma ser um elemento de captação e proteção hídrica, abrigar uma rica fauna e flora com espécies raras e endêmicas ou em extinção. $O$ Pau - Brasil, a Maçaranduba e o Jatobá são exemplos da flora existente, enquanto que da fauna cita-se o macaco Guariba e os Sagüis.

\section{Meio Antrópico}

A povoação de Tibau do Sul desenvolveu-se a partir da atividade agrícola. Em 1911 chegou à condição de Distrito, em 1953 à categoria de Vila e em 1963,

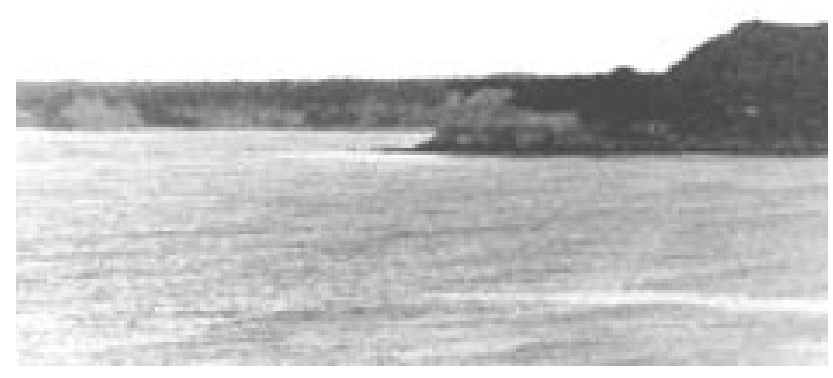

Foto 2 - Vista das falésias de Tibau do Sul.

desmembrou-se de Goianinha. Aárea a ser instalado o empreendimento é desabitada e sem qualquer atividade industrial e comercial. Observam-se apenas alguns lotes rurais e empreendimentos hoteleiros.

\section{IDENTIFICAÇÃO E AVALIAÇÃO DE IMPACTOS AMBIENTAIS}

\section{Matriz de Impactos}

A matriz de impactos gerada compõe-se dos impactos ambientais considerados neste trabalho, numerados e destacadas de forma a melhor identificação dos mesmos (Tabela 1).

\section{SÍNTESE DOS RESULTADOS DA AVALIAÇÃO QUALITATIVA DOS IMPACTOS AMBIENTAIS}

Baseado na matriz de identificação de impactos ambientais da área em estudo se observam diversos impactos não-significativos em ambas às fases do empreendimento; ao passo que os impactos significativos positivos se apresentam em menor número. Tais impactos significativos limitam-se a contratos de trabalho e preservação do solo. Os riscos significativos negativos são advindos da geração de resíduos e do consumo de recursos hídricos, dependendo mais de uma administração criteriosa e bem planejada das atividades, tanto durante a fase de construção quanto de operação, do que da implementação de medidas de controle. Os impactos significativos negativos são em maior número e precisam ser controlados e minimizados através de medidas de controle, que quando não efetivadas causarão sérios danos aos meios físicos, biológicos e antrópico. 
Tabela 1 - Matriz de impactos.

\begin{tabular}{|c|c|c|c|c|c|c|c|c|c|c|c|c|c|c|c|c|c|}
\hline \multicolumn{16}{|c|}{ Matriz de Identificação de Impactos Ambientais da Área em Estudo } & & \\
\hline \multirow{2}{*}{\multicolumn{2}{|c|}{ Importância }} & \multicolumn{14}{|c|}{ Ações do empreendimento } & & \\
\hline & & & & & & ase de & constri & çcão & & & & & Fase de op & ração & & & \\
\hline \multicolumn{2}{|r|}{ Elementos do Meio } & 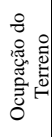 & 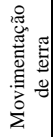 & 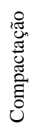 & 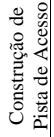 & 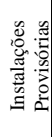 & 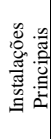 & 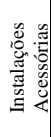 & 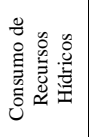 & 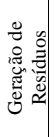 & 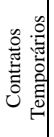 & 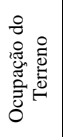 & 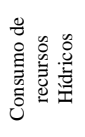 & 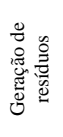 & $\begin{array}{l}\stackrel{0}{\tilde{E}} \\
\text { है }\end{array}$ & & \\
\hline Clima & Mudanças micro-climáticas & & & & & & & & & & & & & & & & \\
\hline \multirow[t]{2}{*}{ Atmosfera } & Qualidade do ar & & 2 & 2 & 2 & & & & & & & & & & & & \\
\hline & Ruído & & 3 & 3 & 3 & 3 & 3 & 3 & & & & 13 & & & & & \\
\hline \multirow[t]{2}{*}{ Solos } & Estrutura & & 4 & 4 & 4 & & & & & & & 14 & & & & & \\
\hline & Erosão & & 5 & & 5 & & & & & & & 15 & & & & & \\
\hline \multirow[t]{2}{*}{ Hidrologia } & Águas superficiais & & 6 & & & & & & & & & & & & & & \\
\hline & Águas subterrâneas & & & & & & & & & & & & 17 & 18 & & & \\
\hline \multirow{3}{*}{$\begin{array}{l}\text { Vegetação e } \\
\text { Fauna }\end{array}$} & Ecossistemas terrestres & & 7 & 7 & & & & 1 & & 9 & & & & 19 & & & \\
\hline & Ecossistemas Aquáticos & & & & & & & & & & & & & & & \multicolumn{2}{|r|}{ Impactos } \\
\hline & Espécies frágeis e ameaçadas & & 8 & 8 & 8 & 8 & 8 & 8 & & 10 & & & & 20 & & & Significativo negativo \\
\hline Paisagem & Qualidade paisagística & & & & & & & & & 11 & & & & 21 & & and & 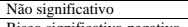 \\
\hline \multirow{2}{*}{$\begin{array}{l}\text { Meio } \\
\text { Antrópico }\end{array}$} & Emprego & & & & & & & & & & 112 & & & & 22 & & \begin{tabular}{|l} 
Risco significativo negativo \\
Não determinado
\end{tabular} \\
\hline & Uso do solo & 1 & & & & & & & & & & 16 & & & & $\mathrm{~m} \mathrm{~m}$ & Significativo positivo \\
\hline
\end{tabular}

\section{MEDIDAS DE CONTROLE E MINIMIZADORAS DE IMPACTOS AMBIENTAIS}

A) Medidas de Controle propostas para fase de construção

\section{1) Mudança nos usos e ocupação do solo na área destinada ao hotel}

Não existe uma única medida de controle para evitar ou minorar os impactos negativos gerados pelas mudanças nos usos do solo local do hotel. O cuidado no planejamento e execução das medidas de controle propostas deverá minimizar os efeitos negativos sobre a área. Como medida compensatória, propõe-se o cultivo do jardim tropical e reflorestamento com espécies autóctones na área destinada ao hotel.

\section{2) Alteração da qualidade do ar pelos poluentes e poeira}

Na terraplenagem e demais obras que envolvam movimentação de terras, deve-se utilizar água para evitar a formação de poeira. Os equipamentos empregados na construção deverão minimizar a emissão de poluentes resultantes da queima de combustíveis fósseis.

\section{3) Geração de altos níveis de ruídos}

Propõe-se o uso de abafadores de som nos equipamentos e o uso de protetores de ouvido pelos empregados, principalmente durante o emprego de máquinas pesadas.

\section{4) Alteração da estrutura do solo pelas ações da obra}

Deve-se limitar o trânsito de veículos envolvidos na construção em áreas que não serão modificadas com a implementação do empreendimento.
5) Erosão dos solos provocada pelas ações de movimentação de terra e construção da pista de acesso

Para tanto se deve evitar o acúmulo de quantidades significativas de sedimentos e criar barreiras de contensão. O volume de escavação deverá ser controlado pelas necessidades de material, evitando assim acúmulos de sedimentos esperando a ser utilizado. $O$ empreendimento deverá ser construído a uma distância mínima de $100 \mathrm{~m}$ da borda da falésia visando reduzir o risco de colapso.

\section{6) Risco de afetação das águas superficiais pela movimentação de terras}

Neste caso deve-se reutilizar a camada do solo com cobertura vegetal em áreas que, pelas diferentes ações da obra o solo ficou nu e desprotegido.

7) Alteração ocorrida na vegetação e fauna dos ecossistemas terrestres devido à movimentação de terra e compactação

Deve-se limitar as ações somente aos pontos do terreno que sofrerão alteração, deixando intacta a área do terreno que será preservada com vegetação nativa.

8) Alteração do ecossistema terrestre, espécies frágeis e ameaçadas de extinção e na qualidade paisagística devido à geração de resíduos.

Propõe-se evitar o acúmulo de resíduos provenientes de podação, movimento de terra, e entulho de construção através da remoção diária por caçambas para o aterro sanitário.

B) Medidas de Controle propostas para fase de operação 
1) Geração de altos níveis de ruído derivados da operação do complexo hoteleiro

Para tanto se deve isolar acusticamente as áreas destinadas à boate, bar, restaurante, cozinha, lavanderia, e demais áreas passíveis de controle sonoro.

\section{2) Mudança nos usos e ocupação do solo na área destinada ao hotel.}

Garantir a adequação no planejamento e execução das medidas mitigadoras a serem adotadas minimiza os efeitos negativos deste aspecto sobre a área.

\section{3) Risco de afetação das águas subterrâneas pelo consumo de recursos hídricos e lançamento de efluentes tratados}

Propõe-se a realização de um estudo da oferta hídrica na região do hotel e o monitoramento da qualidade do esgoto lançado nas valas de infiltração, garantem que não haverá interferência no lençol freático.

4) Alterações na vegetação e fauna dos ecossistemas terrestres, nas espécies frágeis e ameaçadas de extinção e na qualidade paisagística devido à geração de resíduos.

Os resíduos sólidos devem ser mantidos em lixeira fechada e localizada em área de difícil acesso a animais silvestres. Deverão ser retirados diariamente através de caminhão basculante e destinados ao aterro sanitário.

\section{CONCLUSÃO}

O cumprimento das ações propostas neste trabalho, garante a instalação do empreendimento na região, haja vista que o território já abriga outros complexos hoteleiros de menor ou igual porte. Há de se considerar que entre as medidas compensatórias deve figurar a contratação de mão-de-obra local, tanto na fase de construção quanto na de operação. Uma outra medida compensatória seria a criação de um fundo de participação nos lucros do empreendimento com vistas a financiar projetos de monitoramento e gestão ambiental na região do município onde se localiza o complexo hoteleiro. Não foram registrados na região casos de degradação ambiental significativa devido à implementação de tais complexos, sempre que foram seguidas as normas ambientais federais e estaduais vigentes.

\section{REFERÊNCIA}

IDEMA/RN. 1999. Informativo municipal. Município de Tibau do Sul. Natal: Instituto de Desenvolvimento Econômico e Meio Ambiente do RN. 